OPEN ACCESS

Edited by:

Ole Mikkelsen,

Sequoia Scientific, Inc., United States

Reviewed by:

Shaowei Zhang

Institute of Deep-Sea Science and Engineering (CAS), China

Jun Choi,

Pukyong National University,

South Korea

*Correspondence:

Yeon S. Chang

yeonschang@kiost.ac.kr

Jong Dae Do

jddo@kiost.ac.kr

Specialty section: This article was submitted to

Ocean Observation,

a section of the journal

Frontiers in Marine Science

Received: 16 February 2021 Accepted: 04 August 2021

Published: 20 August 2021

Citation:

Jin J-Y, Dae Do J, Park J-S,

Park JS, Lee B, Hong S-D, Moon S-J,

Hwang KC and Chang YS (2021)

Intelligent Buoy System (INBUS):

Automatic Lifting Observation System

for Macrotidal Coastal Waters.

Front. Mar. Sci. 8:668673.

doi: 10.3389/fmars.2021.668673

\title{
Intelligent Buoy System (INBUS): Automatic Lifting Observation System for Macrotidal Coastal Waters
}

Jae-Youll Jin', Jong Dae Do ${ }^{1 *}$, Jin-Soon Park' ${ }^{2}$, Jun Seok Park' ${ }^{2}$ Byunggil Lee ${ }^{1}$,
Sung-Doo Hong ${ }^{3}$, Sung-Ju Moon ${ }^{3}$, Keun Choon Hwang ${ }^{2}$ and Yeon S. Chang ${ }^{4 *}$

${ }^{1}$ East Sea Environment Research Center, Korea Institute of Ocean Science and Technology, Busan, South Korea, ${ }^{2}$ Coastal Development and Ocean Energy Research Center, Korea Institute of Ocean Science and Technology, Busan, South Korea, ${ }^{3}$ OCEANTECH Co., Ltd., Goyang-si, South Korea, ${ }^{4}$ Maritime ICT R\&D Center, Korea Institute of Ocean Science

and Technology, Busan, South Korea

The west coast of South Korea is characterized by a wide macrotidal area with a maximum tidal range of $\sim 10 \mathrm{~m}$. The sea surface elevation varies with the tidal phase, which leads to significant changes in the vertical structure of the physical, chemical, and biological properties of the water column, especially when the interaction by waves and/or the freshwater and sediment input from the river increases. Under such conditions, it is difficult to carry out continuous and consistent measurements of the vertical structures of the water qualities using a conventional observation system that is fixed to the seabed or sea surface because the thickness of the water column constantly changes. Based on the demand for long-term observations of the vertical structures of the water properties in macrotidal environments, the Intelligent Buoy System (INBUS) was developed by the Korea Institute of Ocean Science and Technology (KIOST). INBUS is a buoy equipped with an instrument frame, which is similar to other buoys that are fixed to the sea surface. During every measurement, INBUS detects the water depth and sends the frame down to the seabed to measure the water quality at every vertical level set up in the system. For example, if $N$ levels are set in INBUS, the water depth of each measurement is divided by $N$ layers and the instruments in the lifting frame measure the water properties of each of the $N$ layers while they are descending to the bottom. Based on this procedure, the vertical structure of the water column is consistently measured in $N$ layers regardless of changes of the water depth due to tides and waves. The lifting and measuring process is automatically controlled by INBUS once it is set up in the system. In addition, because INBUS allows bidirectional communication through code division multiple access (CDMA), the system can be controlled by stations on land. If the CDMA communication becomes inoperable owing to extreme wave conditions or the buoy is lost because of incidents such as a collision with a ship, the location of INBUS can be tracked by low-earth-orbit satellites.

Keywords: observation system, automatic lifting, buoy, macrotidal, acoustic instrument 


\section{INTRODUCTION}

Coastal waters are interfaces between land and ocean and thus are important for human life because of their geographical proximity as well as their function as food, transportation, and recreation sources. The environment of coastal waters varies because of the continuous interaction between water and land. For example, the waves shoal and break when they propagate into shallower water, which releases a large amount of energy in the coastal zone, leading to various processes, such as beach erosion, which can cause environmental and economic damage (Alexandrakis et al., 2015). In addition, the tidal range increases in the coastal zone with the propagation of the water into shallow areas, which can result in differences on the scale of meters in the water level between low and high tides.

Various systems have been utilized to observe coastal waters. Because of the relatively shallow water depth compared with the open ocean, instruments are generally mounted on a frame that is fixed to the seabed. One example of a bottom-fixed instrument is a wave gauge that measures the pressure of the water column and converts it into surface elevation based on linear wave theory. Similarly, acoustic sensors, such as the Nortek Acoustic Wave and Current Profiler (AWAC; Pedersen et al., 2007), are mounted on a bottom-fixed frame facing upward to measure waves and currents (Jeong et al., 2020). In addition to wave and current measurements, the instruments fixed to the seabed can be used to measure the near-bed properties such as the sediment concentration and seabed morphology (Do et al., 2019). Other examples of observation systems that are commonly applied in coastal waters include surface buoys that measure nearsurface properties and atmospheric data. Two types of surface buoys are available: surface-following buoys and mooring buoys. Surface-following buoys are based on the global positioning system (GPS) and are widely used for ocean wave measurements (Herbers et al., 2012). Mooring buoys are surface buoys that are moored in coastal waters to measure physical, meteorological, and biogeochemical data (Dorman and Winant, 1995; Bailey et al., 2019). They are connected to the seabed by mooring lines and facilitate observation of the subsurface water column via instruments attached to the mooring lines.

The west coast of South Korea has a wide tidal range, with a maximum value of $\sim 10 \mathrm{~m}$ because of the well-developed amphidromic point and strong tidal currents in the Yellow Sea (Kang, 1984; Yanagi and Inoue, 1995; Hwang et al., 2014). The large difference in the water level during the tidal cycle including waves and currents leads to spatiotemporal changes in the physical, chemical, and biological characteristics of the water throughout the water column (Cadier et al., 2017). However, the timely measurement of these properties is constrained because of the rapid change in the sea surface elevation. Neither of the observation systems discussed above, that is, instruments fixed to the seabed or mounted on a surface buoy, can detect the vertical structures of water properties in macrotidal regions because the water depth significantly changes. Therefore, to measure the variations of the properties within the water column on a timely basis, the vertical locations of the measuring points should be adjusted based on the changes in the surface elevation, which requires the development of an instrumentation system that is specifically suited for macrotidal environments.

In this paper, a suitable buoy system developed by Korea Institute of Ocean Science and Technology (KIOST) - called the Intelligent Buoy System (INBUS) - is described. INBUS is an automatic lifting-buoy system that sends the frame including instruments down to the seabed, and can measure the water quality at every vertical level delineated beforehand in the system. Furthermore, it differs from mooring buoys. In mooring buoys, the subsurface instruments attached to the mooring lines change their vertical positions with the surface elevation changes in the macrotidal environment and thus cannot measure the water properties in a fixed vertical coordinate system. Moreover, in macrotidal areas such as the Yellow Sea, which is a shallow (average depth of $44 \mathrm{~m}$ ) marginal sea bounded by China and the Korean Peninsula (Hwang et al., 2014), the subsurface instruments connected to a mooring line may touch the seabed during low tides, which can lead to the contamination of the obtained data and even damage to the sensors. In contrast, by sending the instrument frame to the seabed INBUS can monitor the time variation of the vertical structure of various water properties. It can measure the properties at fixed positions in the normalized vertical coordinate system (i.e., INBUS can measure the data in a sigma coordinate in which the vertical grids follow the terrain such that the same number of vertical grid points are present regardless of water depth).

Various observation systems similar to INBUS currently exist, however, they all lack some of its key functionalities. The Marel Seine Bay Network (MSBN) developed by Ifremer, France is a real-time unmanned monitoring system for coastal environments (Woerther and Grouhel, 1998). MSBN consists of multiple buoys that measure data at different vertical levels and uses internet protocol and satellite communication for data transfer. However, MSBN does not have the automatic elevation system used by INBUS. Monitoring Your Sound (MYSound) is a real-time monitoring project for water environments, specifically in the areas near Long Island Sound, controlled by the U.S. Environmental Protection Agency (Tedesco et al., 2003). MYSound also consists of multiple stations located onshore and offshore, with observational buoys deployed to measure water qualities. The data are available in real time through the internet. Similar to MSBN, MYSound also does not have the automatic elevation system used by INBUS; it measures data at fixed vertical levels. Monitoring buoys that use an automatic elevation system similar to INBUS also exist (Fowler et al., 1997; Tercier-Waeber et al., 1999). However, the lowest water depths that the sensors can reach are fixed in these buoys so that they are not optimized for macrotidal environment. One of the advantages of INBUS is that it is optimized in macrotidal areas because it can detect the water depth using an altimeter and thus the lowest water depth and the vertical measuring levels can be determined in real time.

The remainder of this paper is organized as follows. Section "Development of INBUS" presents the motivation and development history of the various versions of INBUS. Section "Methods" describes in detail the structure and functions of INBUS. Sections "Results" and "Discussion" provide examples 


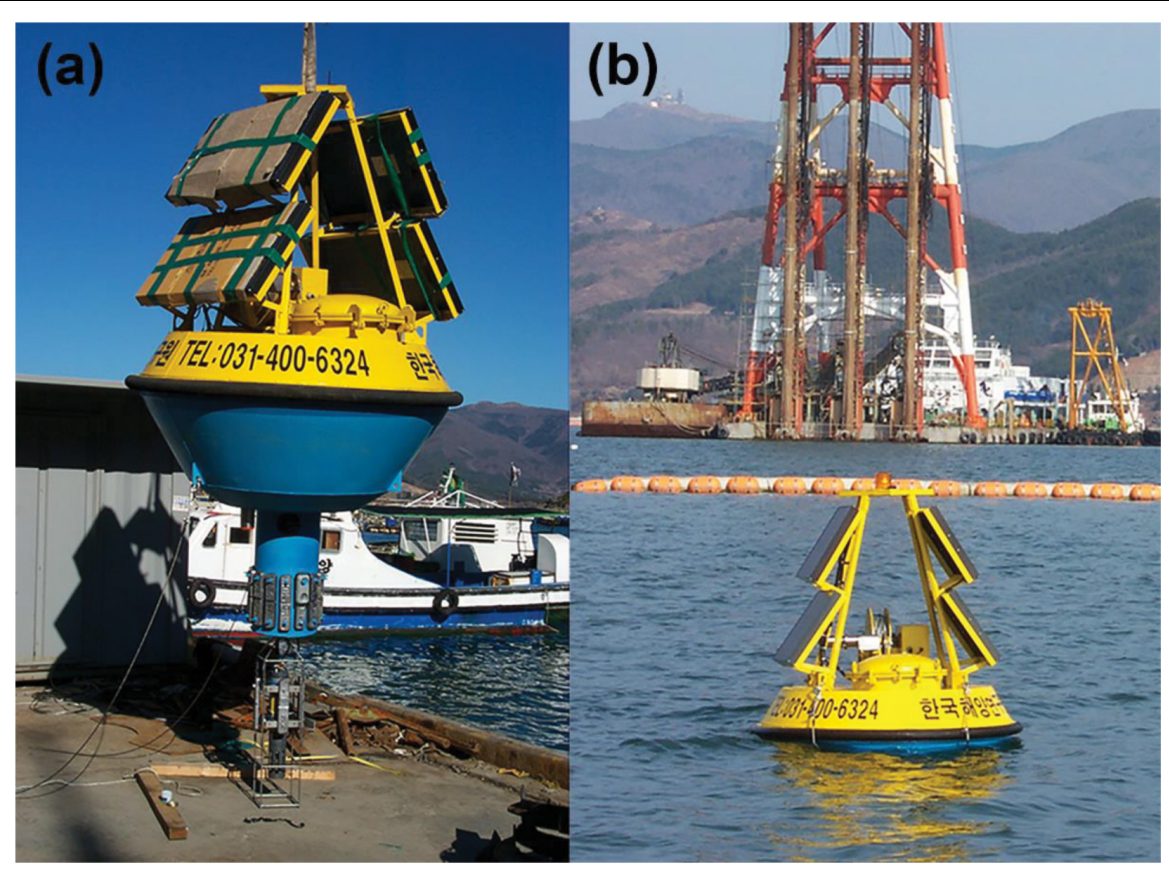

FIGURE 1 | (a) Photograph of Intelligent Buoy System (INBUS)-1 before mooring, (b) photograph of INBUS-1 after mooring.

of application to coastal observations in macrotidal areas and discussions on the current INBUS, respectively.

\section{DEVELOPMENT OF INBUS}

Intelligent Buoy System is an automatic lifting-buoy system developed by Korea Institute of Ocean Science and Technology (KIOST), 2004 that is designed specifically to monitor the marine environment in macrotidal regions with wide tidal ranges. Typical mooring observation buoys cannot effectively monitor the vertical structure of the water column in such regions. On the one hand, if the mooring buoy system is designed for water depths typical for high tides, the sensors attached to their communication cables can touch the seabed. On the other hand, if the system is designed for water depths typical of low tides, the sensors cannot measure data in the deeper part of the water column under high tides. Therefore, INBUS was specifically developed for macrotidal environments as it automatically detects the water depth and sends the sensors downward using an automatic winch system.

The data obtained by INBUS are used as the input for numerical models and for the verification of the model results. These data include the wave height, period, direction, water depth, current velocity, water temperature, salinity, dissolved oxygen (DO) content, conductivity, chlorophyll (Chl) -a content, and turbidity. In addition, meteorological data, such as the air pressure, temperature, and wind speed and direction, are measured by sensors mounted on top of the buoy. These data are transferred to a ground station in real time using code division multiple access (CDMA) communication. INBUS is also equipped with solar panels and thus has self-power capabilities. If there is an emergency, for example, the mooring line of INBUS is disconnected and the system drifts out of CDMA range, the communication system will connect to low-earthorbit (LEO) satellites to locate INBUS, using Iridium satellite communications-which offer global voice and data connectivity through 66 LEO satellites. Since the first generation (INBUS1) was developed in 2003 , its functions have been upgraded and INBUS-2 has been introduced (2009). Figures 1, 2 present photographs of INBUS-1 and 2 before and after mooring, respectively. The figures show that the basic structure of INBUS1 remains unchanged and both systems have similar shapes. Solar panels and antennas are mounted on top of the buoy and a long pipe, which is designed to protect the sensor frame, is attached to the bottom.

The first version of INBUS was initially developed to monitor the water quality only. Atmospheric data and physical parameters, such as wave and current data, were not measured, which limited its application to the analysis of the hydrodynamics and sediment dynamics of the water column depending on the weather conditions. Subsequently, wind and wave gauges and current meters were added to INBUS-2. Because the sensors are automatically sent down to the seabed on a regular basis, they can be damaged during lifting under harsh wave conditions. Because of the real-time monitoring of the wave conditions by INBUS-2, the lifting system of the buoy will not operate during extreme weather and thus the sensors are protected based on the detection of the wave heights. However, data must also be obtained under such harsh conditions because the water quality significantly changes. To continue underwater measurements of the water column even during the gap periods under harsh 


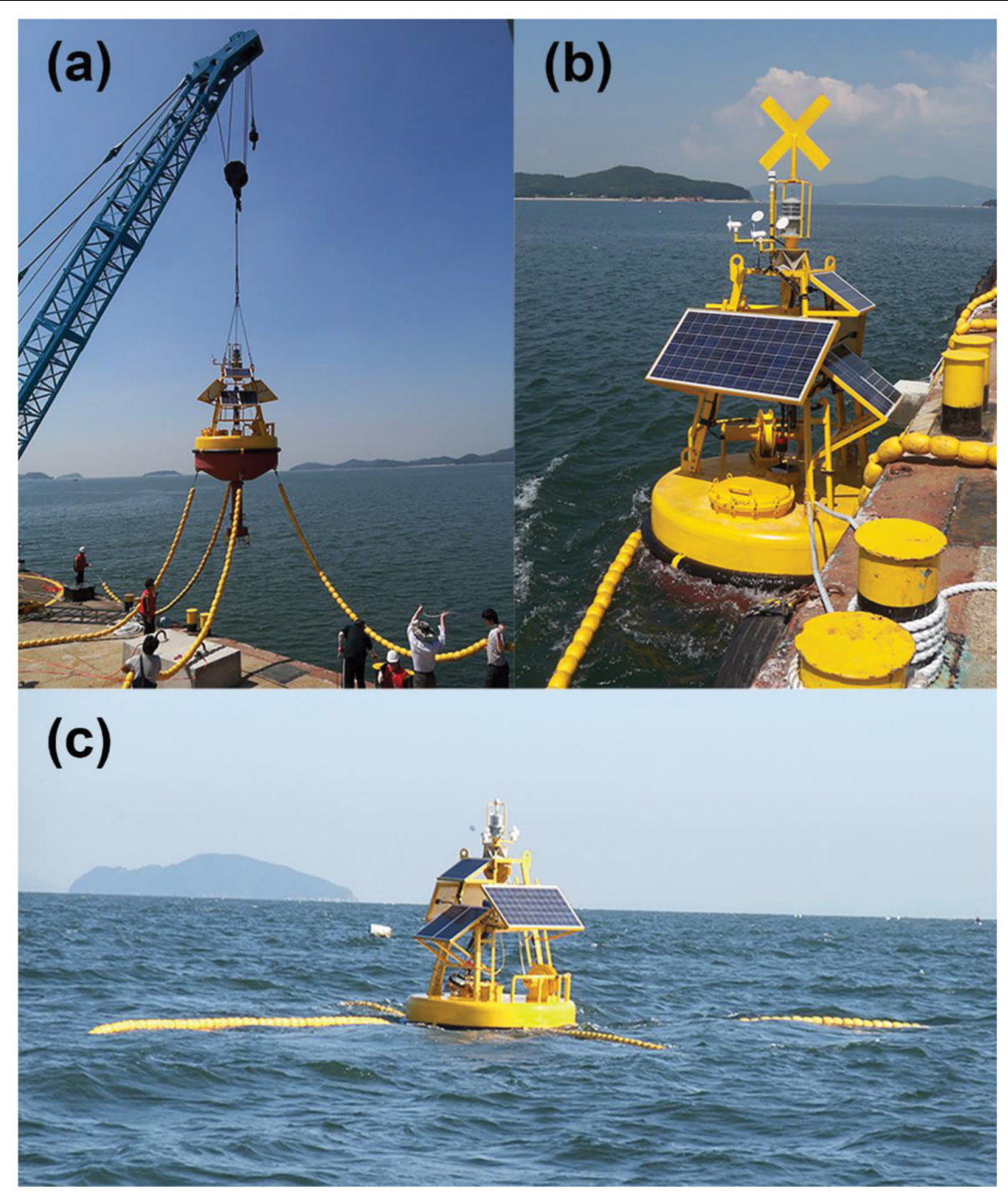

FIGURE 2 | (a,b) Photographs of INBUS-2 before mooring and (c) after mooring.

wave conditions, INBUS-2 is equipped with an acoustic Doppler current profiler (ADCP), which measures the vertical profiles of the currents and indirectly estimates the suspended sediment concentration (SSC) of the water column.

Currently, a third version of INBUS (INBUS-3) is being developed. INBUS-3 will be equipped with a laser in situ scattering and transmissometery (LISST) sensor that can directly measure the SSC for data calibration. In addition, a line of optical backscatter sensors (OBSs) will be installed in the bottom of the sensor frame of INBUS-3 to measure the near-bed SSC because there is a gap in the vertical detection range of INBUS-2 of $\sim 1 \mathrm{~m}$ near the seabed, although the frame is sent down close to the bottom. Therefore, it is expected that INBUS-3 will be able to accurately measure the SSC close to the seabed, which is particularly important to understand the near-bed sediment dynamics. In the following sections, the structure, functions, and sensors of the latest version of INBUS are described in detail.

\section{METHODS}

\section{Intelligent Buoy System Structure}

Figure 3 shows schematic drawings of INBUS-2 (which is currently operated in the field), including upgraded sensors and functions. The new functions of INBUS-3 are not introduced in this section because its development has not been completed yet. INBUS-2 has a hull shape with a long pipe. The height, width, and weight of INBUS-2 are $4.8 \mathrm{~m}$ (2.8 $\mathrm{m}$ underwater and $2.0 \mathrm{~m}$ in the air), $2.5 \mathrm{~m}$, and $\sim 2,170 \mathrm{~kg}$, respectively. A weight is added to the bottom of the pipe to stabilize the buoy by lowering the center of gravity. At the top of the buoy, wind sensors and antennas are mounted on a trapezoid frame. Two symmetrical frames are designed for the self-powered solar panels to achieve stability. The main console, including the main and underwater sensor controllers, is inside the battery hull. A winch is installed below the solar frames to automatically control the lifting system of 

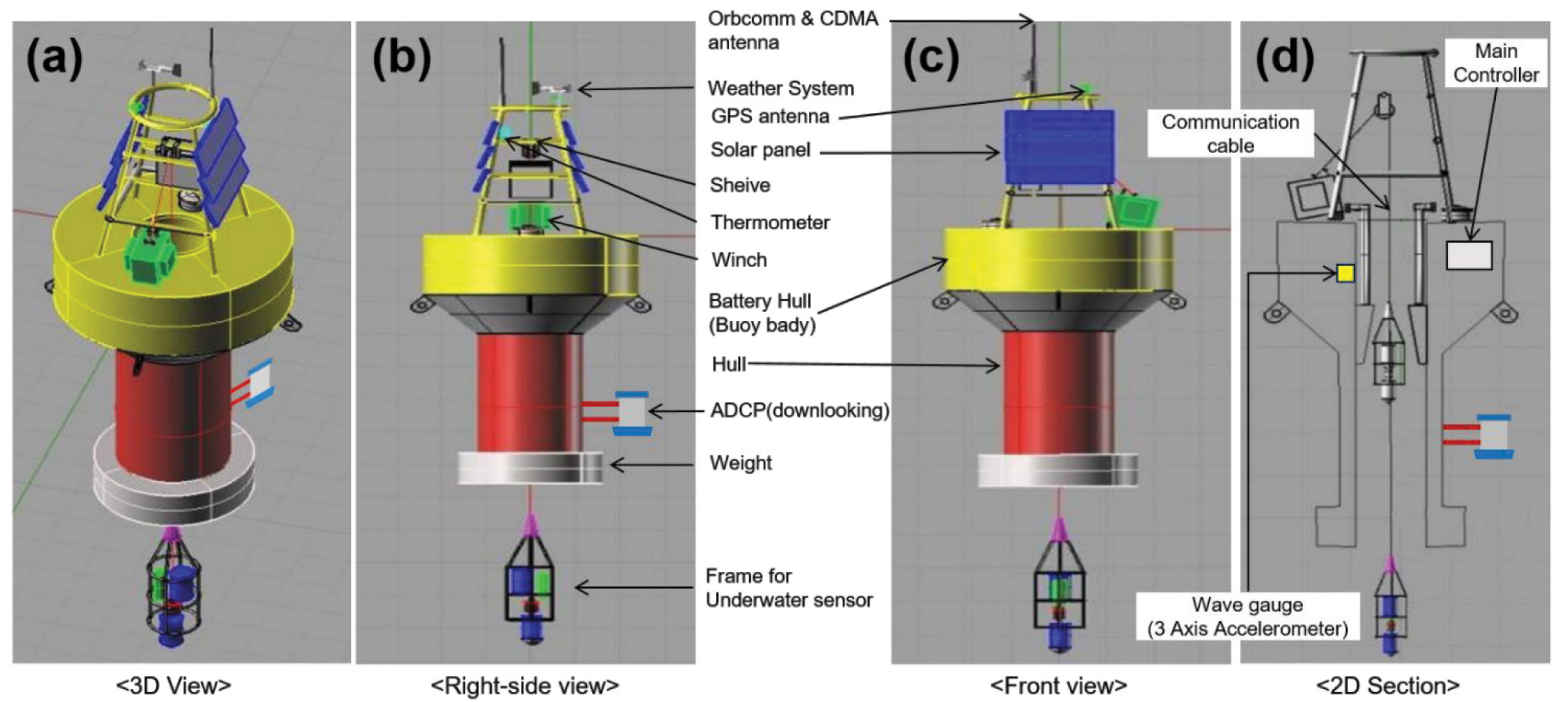

FIGURE 3 | (a) Schematic of INBUS-2 (the current INBUS generation operated in the field). (b) Right-side and (c) front views including the description of the equipment and sensors. (d) Two dimensional section view showing the inner part of INBUS.

TABLE 1 | Power supply configuration of INBUS-2.

\begin{tabular}{|c|c|c|c|c|}
\hline \multirow[t]{2}{*}{ Operating part } & \multicolumn{2}{|c|}{ Battery } & \multicolumn{2}{|c|}{ Solar panel } \\
\hline & Applied voltage & Configuration & Applied voltage & Configuration \\
\hline Winch & 24 V $300 \mathrm{Ah}$ & 12 V 2S3P* (12 V 100 Ah 6ea) & 24 V 190 W & 24 V 3P (24 V 190 W 2ea) \\
\hline Main controller & 12 V $600 \mathrm{Ah}$ & 12 V $6 \mathrm{P}$ (12 V 100 Ah 6ea) & 12 V 50 W & 12 V 3P (12 V 50 W 3ea) \\
\hline
\end{tabular}

${ }^{*}$ S, series connection; $P$, parallel connection

the underwater sensors. Two batteries are installed in the battery hull on the opposite side of the winch to stabilize the buoy as they support the power for the main controller and winch, respectively. The configuration for the batteries and solar panels are listed in Table 1. In the lower part of INBUS-2, a hull with a pipe shape is attached to the buoy. The center of the hull is empty such that the underwater sensors can move through it when they are lowered/lifted by the winch. The frame with underwater sensors is connected to the winch through the hull and weight. When the sensors are not in operation, they are inside the hull and thus protected from damage by suspended materials or waves. The positions of the equipment and sensors of INBUS-2 are shown in Figure 3.

\section{Intelligent Buoy System Sensors}

As mentioned above, INBUS-2 is self-powered based on the installation of solar panels. In addition, a $12 \mathrm{~V}$ battery is used to support the power system. The INBUS-2 sensors can be divided into five classes: (1) GPS and weather sensors that are mounted on top of the buoy; (2) altimeter and wave gauge, which are used to determine whether the lifting frame should be lowered based on the wave data and to measure the water depth to identify the vertical measuring distance; (3) water quality sensors and current meter, which are installed on the lifting frame to measure the water quality and flow velocity at each vertical level; (4)
ADCP, which is used to measure the vertical current and SSC profiles, under harsh wave conditions when the lifting frame is not operated; and (5) CDMA system, which is used to transfer the real-time data to the ground station and to control INBUS from the ground station. If the buoy is disconnected from the mooring location and drifts away from the CDMA range, INBUS- 2 can be located based on the connection to LEO satellites. The locations of the sensors are marked in Figures 3, 4, and the specifications of the sensors of the five classes are presented in Table 2.

\section{Operation}

The operation procedure of INBUS-2 is as follows:

(1) Wake-up mode: the INBUS is switched from standby to wake-up mode $5 \mathrm{~min}$ prior to the observation to check the settings.

(2) Operation mode test: the main controller checks for command changes (e.g., sensing mode change, forced termination, ADCP reset) from the ground control station.

(3) Application of the changed command: resetting of INBUS according to the changed command (if any) in Step (2).

(4) INBUS status test: checking of the location of INBUS, communication cable loosening, encoder starting point, and emergency stop, INBUS voltage, and CDMA sensitivity. 


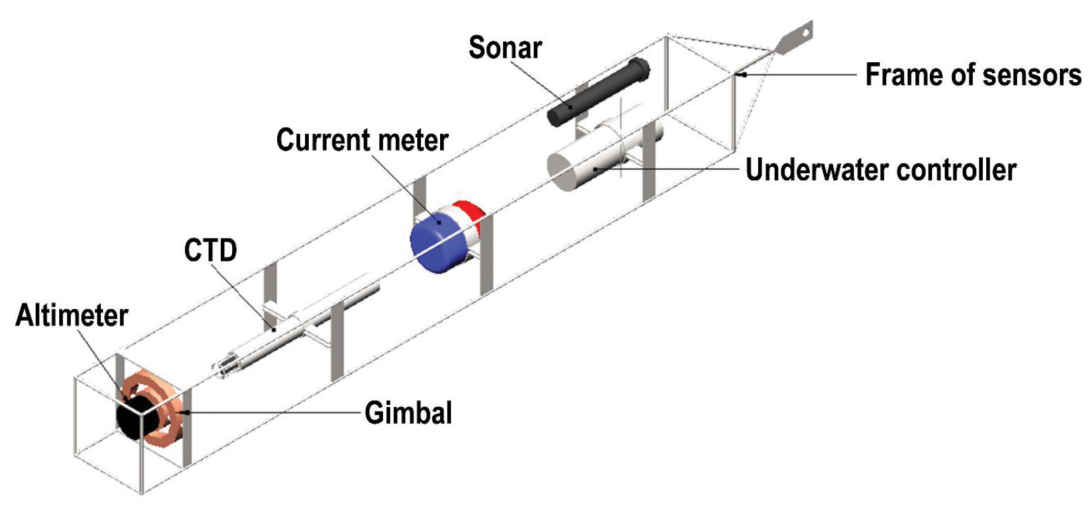

FIGURE 4 | Schematic of the frame marked in Figure 3 and the underwater sensors mounted in the frame.

(5) Warning: if a problem is detected in Step (4), the current status is transmitted to the control station (or user) using the CDMA system. If the INBUS location deviates from the initial location, its current location is transmitted using the CDMA system or a LEO satellite if it is out of the CDMA range.

(6) Positioning of the lifting sensor frame: before the observation begins, the lifting sensor frame is moved to the home position ( $1 \mathrm{~m}$ below the water surface) inside the hull.

(7) Measuring of the weather and wave conditions.

(8) Decision-making for observation: based on the wave conditions measured in Step (7), a decision is made as to whether the lifting sensor frame should be lowered to start the observation.

(9) ADCP observation: the ADCP is set to start the measurement when the frame sensors are lifted. If the frame should not operate owing to harsh wave conditions, the ADCP starts the observation alone.

(10) Measurement of the water depth: if the system works under normal conditions after completing Step (8), the communication cable is lowered to move the lifting sensor frame $2.8 \mathrm{~m}$ below the water surface (first observation layer) outside the hull. The altimeter measures the water depth and divides it into $N$ layers to determine the water depth of layer $N$ for profiling.

(11) Profiling (observations using lifting frame sensors)

(A) 1 st to $N$ - 1th layer:

(A1) When the frame reaches the layer calculated by the altimeter, the water depth is measured again to check if the frame has reached the intended water depth. If it has not, the position of the frame is adjusted.

(A2) Wait time of $1 \mathrm{~min}$ to allow the frame to stabilize; subsequently, the sensor measurements start (1 min).

(A3) The data are saved in a data logger and a secure digital (SD) memory card for backup.

(A4) INBUS status check: same procedure as Step (4). If the INBUS is operating under normal conditions, the communication cable is lowered to move to the next level.
(B) Nth layer:

(B1) The frame is $1 \mathrm{~m}$ above the seabed (to secure the safety of the sensor).

(B2) Same procedures as described in Steps A2-A4.

(12) Returning to the home position: the winch is operated to move the frame back to the home position ( $1 \mathrm{~m}$ below the water surface) inside the hull.

(13) Data transfer: the data stored on the data logger are transferred to the ground station using the CDMA system.

(14) Standby: the INBUS is switched into standby mode.

The operation procedure of INBUS-2 is summarized by the flowchart in Figure 5.

When errors are detected during the operation of INBUS, an error message is sent to the users to notify them. The users can then fix the problems according to the error message received. The error messages and status updates are listed in Table 3.

\section{Mooring, Automatic Lifting, and Data Transfer System}

For the mooring of INBUS, a two-point mooring line is used considering the strong flow velocity in areas with a high tidal range (Figure 6). Two rows of anchor chains connected to the two weights are used to fix INBUS and minimize buoy movement. Several pressure buoys are attached to the mooring lines made of nylon ropes to prevent collisions and twists between the sensor unit and lines, which might occur when the lines loosen during low tides. The weights are placed onto the seabed perpendicular to the tidal current direction to increase the stability. In addition to the weights, four anchors are installed on both sides of the weights. The mooring system of INBUS-2 is illustrated in Figure 6. The lengths of the anchor chains and mooring lines marked in Figure 6 are the distances between the sinkers and buoy used to prevent collisions and twists when the water depth is $15 \mathrm{~m}$ with a maximum tidal range of $9 \mathrm{~m}$.

The automatic lifting system (ALS) consists of the winch and main controller, with the main controller deciding when and the length of communication cable to be lowered for reaching the destination levels from the winch. The winch consists of a motor, drum, reducer, SlipRing, communication 
cable holder, waterproof housing, and supporter (Figure 7). The motor and reducer rewind the communication cables on the drum. The SlipRing protects the data transferred through the communication cables when they are rewound on the drum. The communication cable holder keeps the communication cables on the drum during rewinding. The motor, reducer, and SlipRing are waterproof and protected by a housing. The specifications of the winch system are presented in Table 4.

The efficiency of the reducer [(power of output shaft)/(power of input shaft) $\times 100$ ] of INBUS-2 is increased by $30 \%$ compared to that of INBUS-1 by directly connecting it to the motor, that is, removing the chains used for the connection to the reducer. The motor is equipped with an electronic break to control the winch and save power when it is not in operation. In winter, the lubricants are often frozen, which reduces the efficiency and lifetime of the system. In INBUS2 , the lubricants are replaced with low-temperature grease and additional oils. In addition, the drum is equipped with bearings on both sides to prevent distortion due to the tension of the communication cables.

TABLE 2 | Specifications of the sensors mounted on INBUS-2.

\begin{tabular}{|c|c|c|}
\hline \multicolumn{3}{|c|}{ Sensor } \\
\hline $\begin{array}{l}\text { Classification } \\
\text { (sensor/manufacturer) }\end{array}$ & Measuring data & Description \\
\hline
\end{tabular}

Weather sensor (PB200/Airmar)

Altimeter (SS510/Airmar) and wave gauge (TinyWave/OTRONIX)

Water quality sensor (YSI6600/YSI; DCS 4100R/Aanderaa)

Current and SSC (ADCP600kHz/RDI)
Wind speed

Wind direction

Air temperature

Air pressure

Water depth

Wave parameter

Current velocity, sensor depth, conductivity, water temperature, salinity, $\mathrm{pH}, \mathrm{DO}, \mathrm{Chl}$, turbidity

Water profiling

Profile parameters

Echo intensity profile

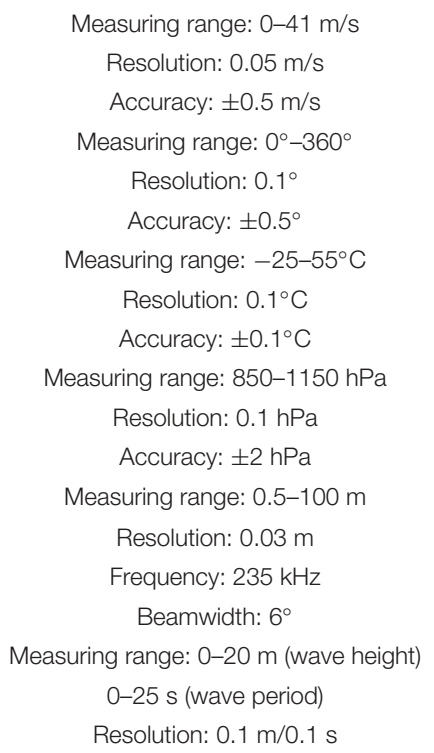

Measuring range: $0-3.0 \mathrm{~m} / \mathrm{s}$ (current speed); $0^{\circ}-360^{\circ}$ (current direction); $-5-45^{\circ} \mathrm{C}$ (temperature); 0-100 $\mathrm{mS} / \mathrm{cm}$ (conductivity); 0-1,000 NTU (turbidity); 0-400 $\mu \mathrm{g} / \mathrm{L}$ (chlorophyl); 0-500 $\mu \mathrm{M}$ (DO). Accuracy: $\pm 0.15 \mathrm{~cm} / \mathrm{s}$ (current speed); $\pm 5^{\circ}$ (current direction); $\pm 0.15^{\circ} \mathrm{C}$ (temperature); $\pm 0.5 \%$ (conductivity); $\pm 2 \mathrm{NTU}$ (turbidity); $0.1 \mu \mathrm{g} / \mathrm{L}$ (chlorophyl); $8 \mu \mathrm{M}$ (DO).

\begin{tabular}{lcc}
\hline Vertical Resolution & Range & Std. Dev \\
\hline $0.5 \mathrm{~m}$ & $38 \mathrm{~m}$ & $14.0 \mathrm{~cm} / \mathrm{s}$ \\
$1.0 \mathrm{~m}$ & $42 \mathrm{~m}$ & $7.0 \mathrm{~cm} / \mathrm{s}$ \\
$2.0 \mathrm{~m}$ & $46 \mathrm{~m}$ & $3.6 \mathrm{~cm} / \mathrm{s}$ \\
$4.0 \mathrm{~m}$ & $51 \mathrm{~m}$ & $1.8 \mathrm{~cm} / \mathrm{s}$ \\
\hline
\end{tabular}

Velocity accuracy: $0.3 \%$ of water velocity relative to $\mathrm{ADCP} \pm 0.3 \mathrm{~cm} / \mathrm{s}$

Velocity resolution: $0.1 \mathrm{~cm} / \mathrm{s}$

Velocity range: $\pm 5 \mathrm{~m} / \mathrm{s}$ default, $\pm 20 \mathrm{~m} / \mathrm{s} \max$

Number of depth cells: 1-255

Ping rate: typical $2 \mathrm{~Hz}$, Max. $10 \mathrm{~Hz}$

Vertical resolution: depth cell size, user configurable

Dynamic range: $80 \mathrm{~dB}$

Precision: $\pm 1.5 \mathrm{~dB}$ 


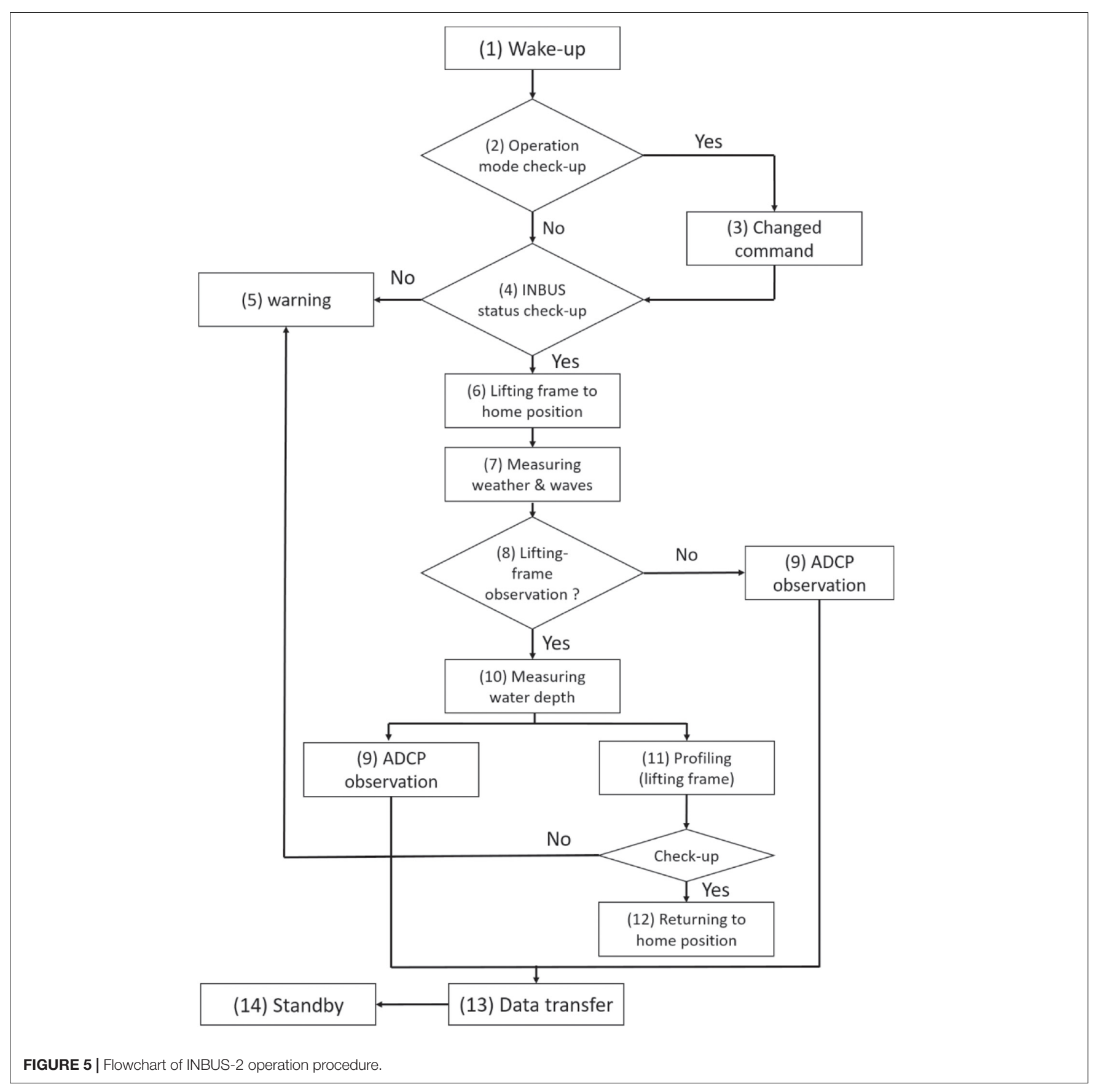

The data measured by INBUS are transferred to the ground station using the CDMA network, which works well even in sea areas in which electronic signals are weak. The data are transferred using a CDMA-to-CDMA system and relay stations such that they can be safely received by the ground station (Figure 8A). The real-time data transferred by the CDMA network can be downloaded from a website. The users can remotely control INBUS by changing the number of observations and water depth of the lifting system. The users can make commands for sampling, emergency stop, or winch recovery. When an error occurs in INBUS, an error message is sent to the smartphone of the user without interference from the firewall. If INBUS is disconnected from the mooring system and drifts away from the CDMA area, the communication system connects to the Iridium satellites. Figure $\mathbf{8 B}$ shows the Iridium system. The users directly receive information from the Iridium station and can track the location of INBUS in real time.

\section{RESULTS}

In this section, examples of INBUS data are presented and analyzed to discuss the efficiency of the INBUS system in 
TABLE 3 | Error messages and status updates sent from INBUS-2.

\begin{tabular}{|c|c|}
\hline Error message & Status \\
\hline AWS error & $\begin{array}{l}\text { GPS information is not received or weather data are } \\
\text { missing. }\end{array}$ \\
\hline Buoy location error & $\begin{array}{l}\text { The buoy is out of range of the permissible radius with } \\
\text { respect to the initial position. }\end{array}$ \\
\hline Encoder error & $\begin{array}{l}\text { The length of the communication cable cannot be } \\
\text { measured owing to mechanical problems. }\end{array}$ \\
\hline Limit switch error & $\begin{array}{l}\text { The limit switch that checks the position of the lifting sensor } \\
\text { frame is not in operation. }\end{array}$ \\
\hline Motor driver error & $\begin{array}{l}\text { Electric current exceeds the threshold. This can occur } \\
\text { when the water flow velocity is too strong or the buoy is } \\
\text { disturbed by fishing gear (e.g., fishing net). }\end{array}$ \\
\hline $\begin{array}{l}\text { Home recovery } \\
\text { error }\end{array}$ & $\begin{array}{l}\text { The lifting sensor frame did not return to the home position, } \\
\text { which is likely due to mechanical problems or disturbance } \\
\text { by fishing gear. }\end{array}$ \\
\hline UC data error & $\begin{array}{l}\text { The data measured by the lifting frame sensors are not } \\
\text { received by the main controller. }\end{array}$ \\
\hline Profiling error & $\begin{array}{l}\text { Lifting frame sensors cannot be operated owing to high } \\
\text { waves. }\end{array}$ \\
\hline Altimeter error & The altimeter cannot determine the vertical layers. \\
\hline
\end{tabular}

measuring the water properties in macrotidal environments. First, the time variation of the INBUS data measured in the air and water over a period of 1 month was plotted. Data on this scale are useful to analyze the variations in the water properties during the spring and neap tides with maximum and minimum tides, respectively. Second, the properties measured during the spring and neap tides were plotted for a shorter period of $\sim 2$ days.
Based on this scale, the detailed variation in the water column from high to low tide can be visualized and data obtained during the spring and neap tides can be compared, highlighting the performance of INBUS.

\section{Time Variation}

In this study, INBUS data were measured off the west coast of Korea near Incheon Airport (Figure 9). In this region, the semidiurnal tidal cycle can be clearly observed and the spring and neap tides significantly differ. The INBUS-2 system was installed at $\mathrm{P} 1$, which has a mean water depth of $\sim 18 \mathrm{~m}$. The maximum tidal range during spring tide is $\sim 11 \mathrm{~m}$, that is, $>60 \%$ of the mean water depth. The maximum water depth during high tide is $>20 \mathrm{~m}$, whereas the minimum depth during low tide is $\sim 10 \mathrm{~m}$, leading to difficulties measuring the water properties at fixed points in the water column owing to the significant change in the water level. The area is connected to a water channel north of Yeongjong-do Island (airport location), which produces strong tidal currents. Therefore, long-term observations of the water properties are required to monitor the marine environment near the airport. For this purpose, the INBUS-2 system was installed in October 2010 and the air and water properties at P1 were measured until August 2012.

Figures 10, 11 show examples of the data measured by INBUS2 over 24 days from June 1 to 24 . In this period, both the spring and neap tides were observed for comparison. During this experiment, a total of 15 properties were measured by INBUS2 in the air (Figure 10) and water (Figure 11). The weather sensor measured the wind speed, direction (Figures 10a,b),

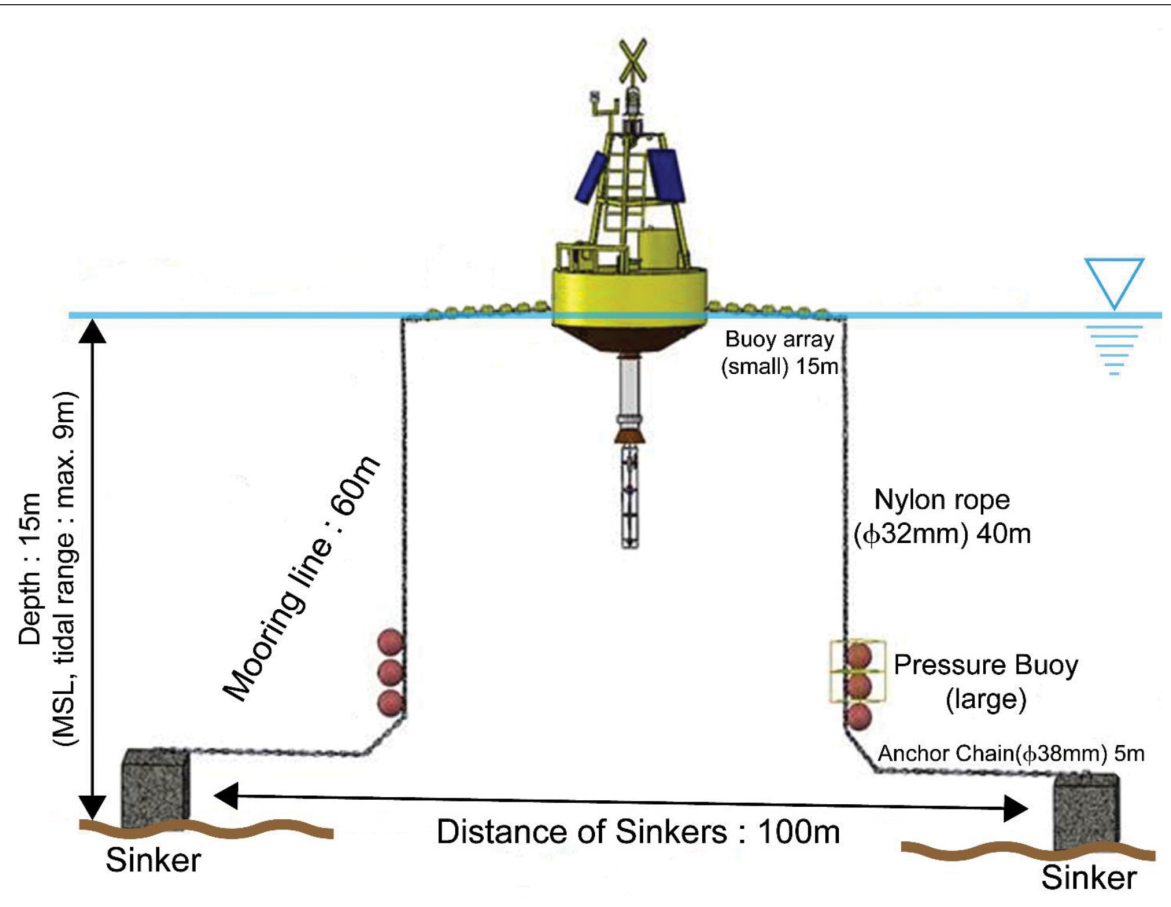

FIGURE 6 | Intelligent Buoy System (INBUS)-2 mooring system. 

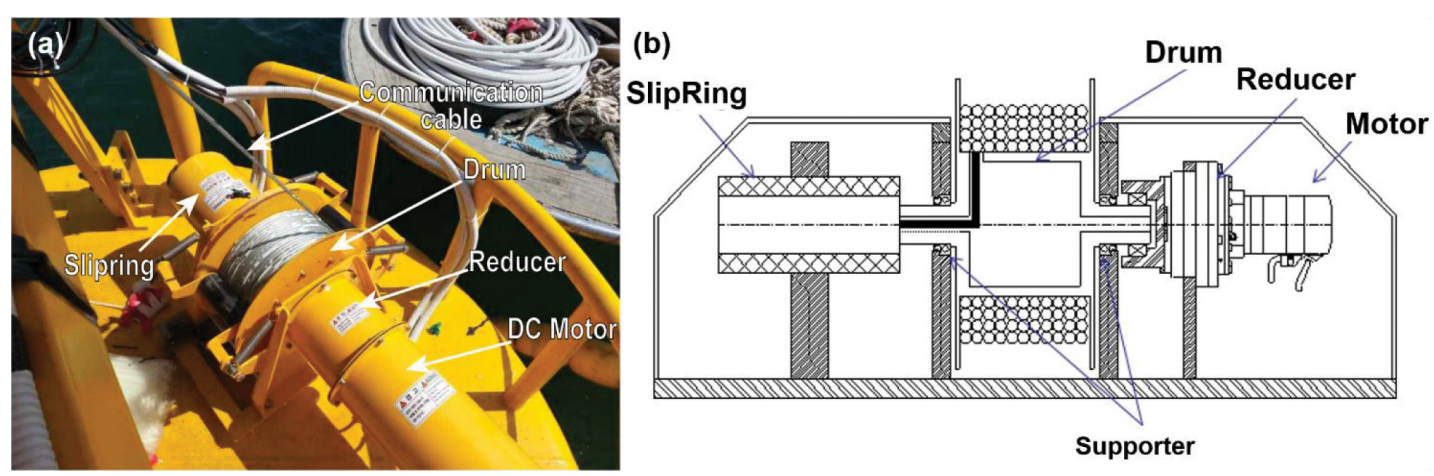

FIGURE 7 | (a) Picture of winch, (b) schematic of winch, which is controlled by the automatic lifting system (ALS).

TABLE 4 | Specifications of the winch mounted on INBUS-2.

\begin{tabular}{ll}
\hline Manufacturer & OCEANTECH Co., Ltd. \\
\hline Model No. & ALE-2460-7DM \\
Material & SUS 316 \\
Specifications & $\bullet$ Cable \\
& -24 AWG $\times 7 \mathrm{c}$ \\
& - Size: approx. $\phi 10 \mathrm{~mm}$ \\
& - weight: approx.0.161 kg/m \\
& - length: $60 \mathrm{~m}$ \\
& $\bullet$ Winding length: $60 \mathrm{~m}$ \\
& $\bullet$ Winding speed: $5 \mathrm{~m} / \mathrm{min}$ \\
& $\bullet$ Winding torque: $15 \mathrm{~kg} . \mathrm{m}$ \\
& $\bullet$ Power source: $24 \mathrm{VDC}, \phi 1,60 \mathrm{~Hz}$ \\
& $\bullet$ SlipRing: $2 \mathrm{~A} \times 7 \mathrm{P}$ \\
& $\bullet$ Total weight: approx.100 kg \\
& $\bullet$ Motor \\
& -24 VDC, $\phi 1,60 \mathrm{~Hz}$ \\
& $-300 \mathrm{~W}, 3000 \mathrm{rpm}, 1 / 600$ \\
$\bullet$ Brake & -24 VDC \\
&
\end{tabular}

and air temperature and pressure (Figures 10d,e). The surface elevation was measured using an altimeter (Figure 11a) and the wave height was measured with TinyWave (Figure 10c). INBUS-2 sent down the lifting frame every $0.5 \mathrm{~h}$ to measure the water properties. Four internal levels were set up for this experiment such that the distance from the lifting frame to the seabed was divided by four during each observation (Figure 11b) and the water quality sensor measured the properties in four internal levels. In this experiment, the current speed and direction (Figures 11c,d), water temperature (Figure 11e), DO content (Figure 11f), Chl concentration (Figure 11g), turbidity (Figure 11h), salinity (Figure 11i), and conductivity (Figure 11j) were measured. In this experiment, the ADCP was not operated and thus current and SSC data are not available.

Based on the total water depth (Figure 11A), the spring tides occurred on June 7 and 21, with a maximum value of $\sim 11 \mathrm{~m}$ (June 7). The neap tide developed on June 14 with a tidal range of $\sim 4 \mathrm{~m}$. During this period, the wind conditions were mild because the wind speed was less than $10 \mathrm{~m} / \mathrm{s}$ (Figure 10a). Accordingly, the wave conditions were mild with wave heights below $0.3 \mathrm{~m}$. Therefore, the main driving forces of the water properties were the tides. Figure $\mathbf{1 1 b}$ shows that the mean water depths of the four internal levels were $\sim 2,7,11$, and $15 \mathrm{~m}$, respectively. With the decrease in the tidal range from the spring tide (June 7) to the neap tide (June 14), the current speed of the first internal layer decreased from the maximum of $\sim 1.4 \mathrm{~m} / \mathrm{s}$ to $\sim 0.6 \mathrm{~m} / \mathrm{s}$ (Figure 11c). However, the current direction, which was $180^{\circ}$ out of phase between the high and low tides, did not change (Figure 11e). During one tidal cycle, the water temperature fluctuates, with a mean difference of $\sim 2^{\circ} \mathrm{C}$, which will be discussed in detail in the next section. The daily mean temperature during the experimental period gradually increased from $\sim 15$ to $\sim 18^{\circ} \mathrm{C}$ with the start of the summer season. The water properties, such as the DO content, Chl concentration, and turbidity, differ in the spring and neap tides. Higher values were obtained during the spring tides under stronger mixing of the surface water due to stronger currents (Figures 11f-h). However, note that the DO and Chl contents were higher during the latter spring tide on June 21 than on June 7 , whereas the tidal range was higher on June 7 . This is likely related to the higher water temperature in the latter spring tide, which increased the primary production. In contrast, the turbidity was greater during the former spring tide because the sediment suspension increased under the stronger tidal current. The salinity and conductivity show similar patterns because the differences between the spring and neap tides were smaller than those of other properties. In contrast, the differences between the high and low tides were significant because higher values were obtained during the low tides (Figures 11i,j), which is likely due to the impact of freshwater inflow from the land (Figure 11).

\section{Difference Between Internal Layers}

In this section, the water properties are compared on a shorter time scale. Figures 12a-g show seven properties (total depth, depths of internal layers, current speed, water temperature, Chl, turbidity, and salinity) that were measured over 2 days starting on June 7 when the first spring tide occurred. Different colors are used to represent the data measured in the four different internal layers. The figures indicate clear 


\section{A}

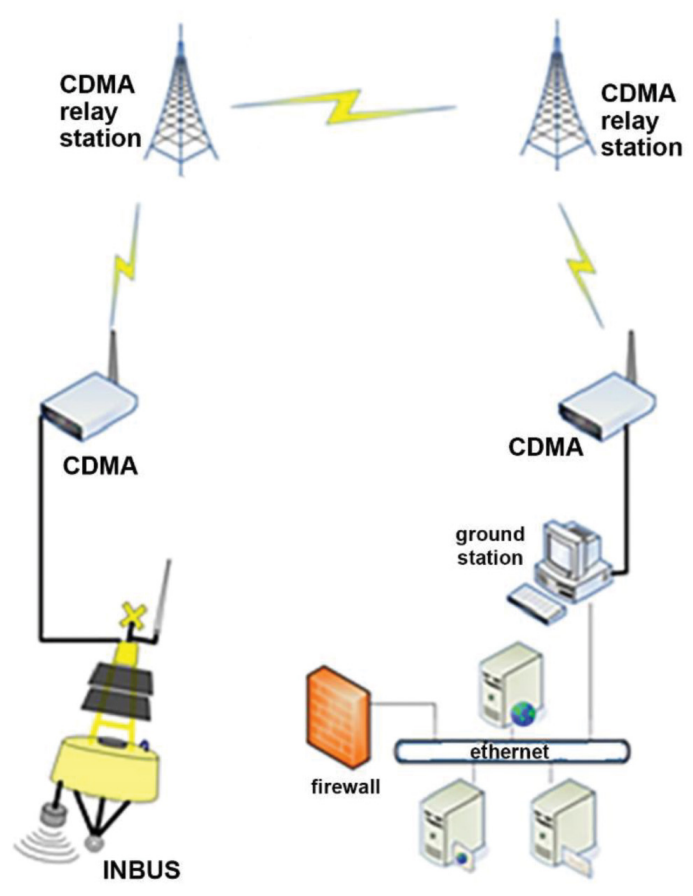

B

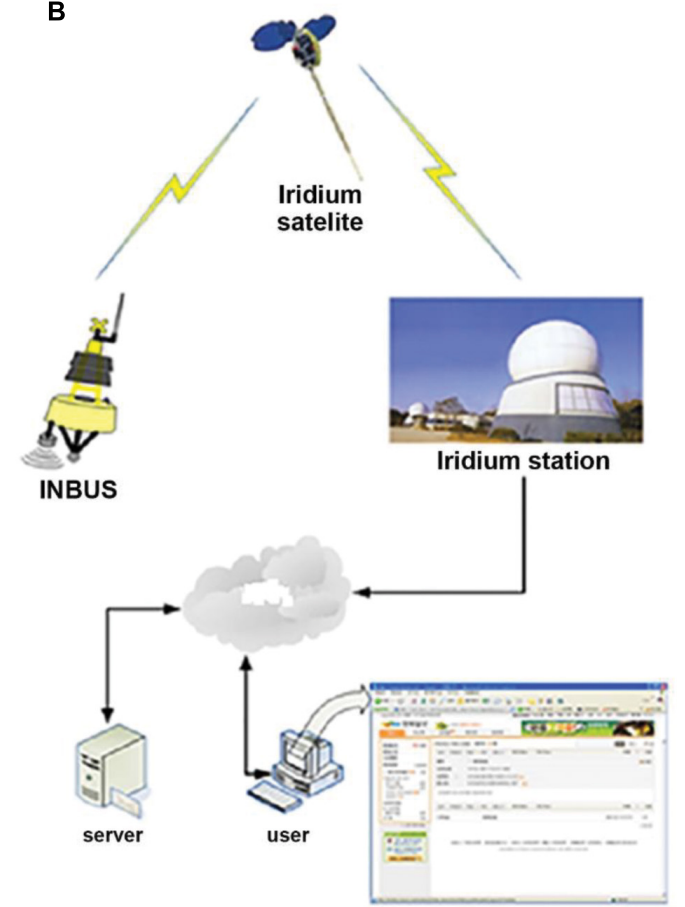

FIGURE 8 | (A) Data transmission system of INBUS-2. (B) Iridium satellite system for the tracking of the location of INBUS after disconnection from the mooring system.

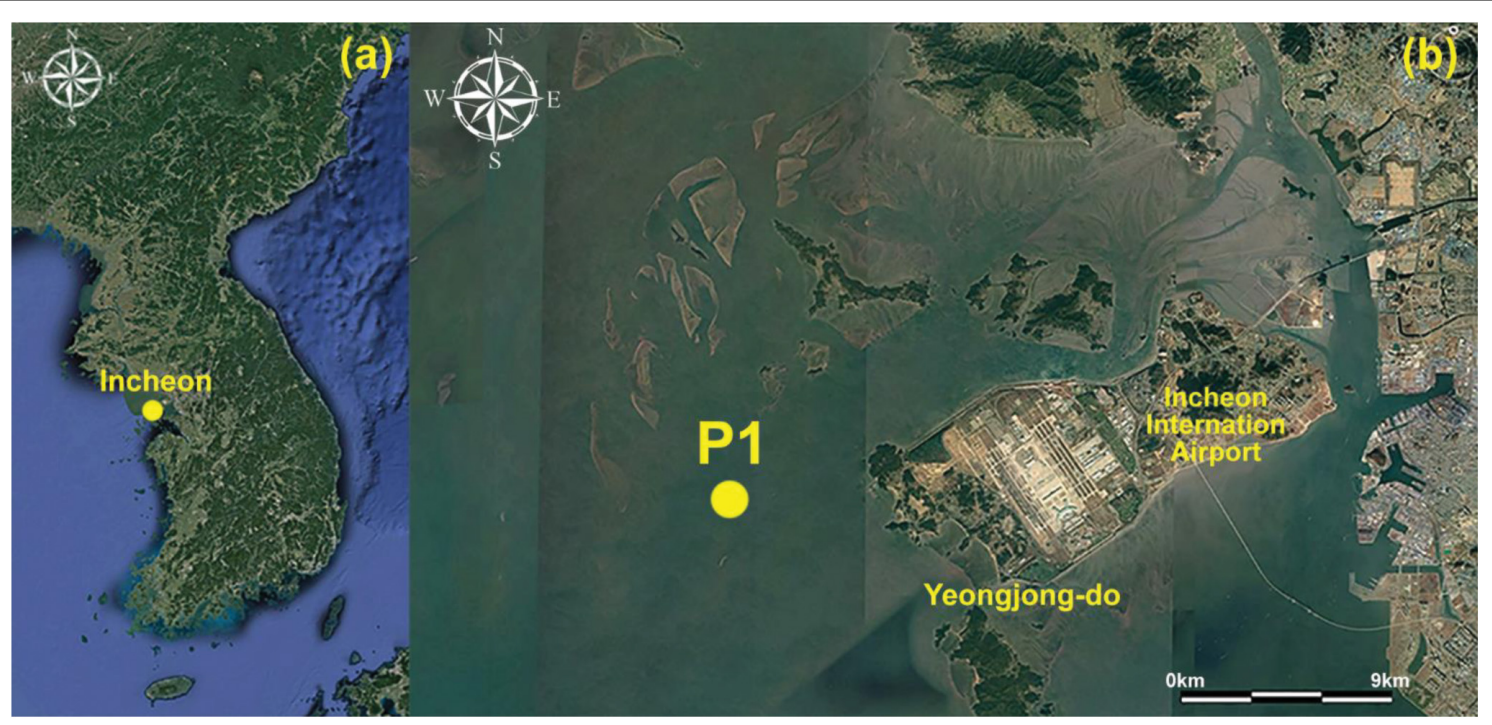

FIGURE 9 | (a,b) Map of the area near Yeongjong-do Island showing location P1 at which INBUS-2 data were measured.

differences between the first (top) and fourth (bottom) layers during the spring tide. The current speed of the top layer $(z<5 \mathrm{~m})$ reached $\sim 1.4 \mathrm{~m} / \mathrm{s}$ in the ebb and flood phases during the spring tide (Figures 12b,c). However, the maximum current speed of the bottom layer was only $\sim 0.8 \mathrm{~m} / \mathrm{s}$ at $\mathrm{z} \sim 15 \mathrm{~m}$, which indicates the stratification of water during the spring tide.
Note that the water temperature is higher and lower during low and high tides, respectively (Figure 12d). The water temperature increased during the high tide in the shallower area in which mud flats developed (Figure 8) and flowed out to the deeper area (close to location P1) with the ebb tide. During the flood phase, the water temperature of the top layer was $1.0-1.5^{\circ} \mathrm{C}$ higher than that of the bottom layer. When the heavier cold water 


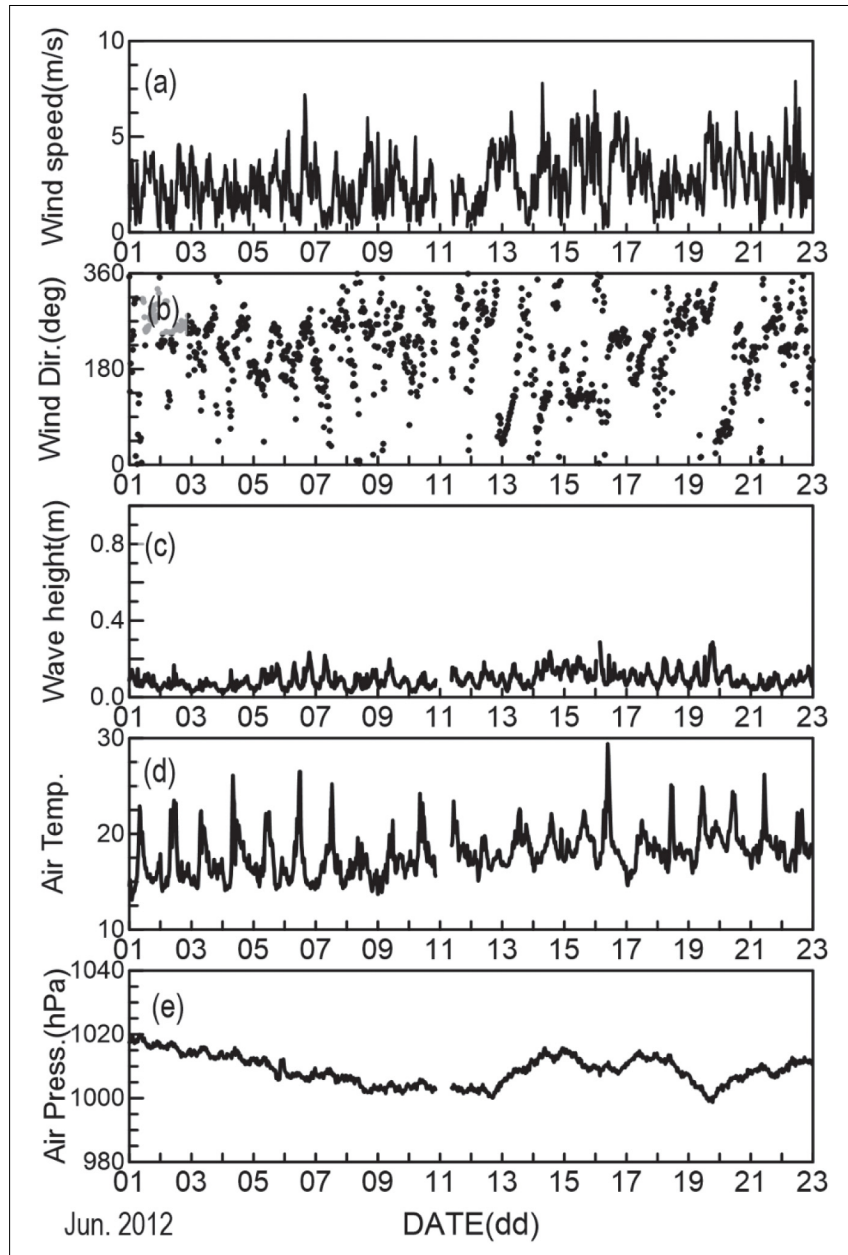

FIGURE 10 | Time variation of air properties measured by INBUS-2 at location P1 from June 1 to 23, 2012: (a) wind speed, (b) wind direction, (c) wave height, (d) air temperature, (e) air pressure.

in the deeper area reached the location with the flooding tide, it occupied the lower layers first owing to its weight, while the water in the top layer remained warm, leading to stratification.

The stratification during the flood phase is also reflected in the salinity data (Figure 12g). In contrast to the temperature, the salinity is higher during high tides and lower during low tides because the warmer but fresher water flows from shallower areas with ebbing tides to the area close to location P1. However, when the colder water with higher salinity flows from the deeper area to the location with the flooding tides, heavier salty water occupies the lower layers first and thus the salinity in the lower layers exceeds that of the top layer. The time-dependent patterns of the $\mathrm{Chl}$ content and turbidity are similar because the corresponding values are higher in the lower layers and lower in the top layer (Figures 12e,f), which is reasonable because a larger quantity of sediments is expected below the surface layer based on their weight. In addition, the maximum $\mathrm{Chl}$ content is generally measured below the surface layer (Loisel et al., 2001). Note that the differences in the $\mathrm{Chl}$ and turbidity values between the top and bottom layers increase in the flood tidal phases. This increase corresponds to the variation in the salinity (Figure 12g), which is due to the intrusion of heavy water from the deeper area during the flooding phase.

In Figures $\mathbf{1 2 h}-\mathbf{n}$, the same properties measured over 2 days starting on June 14 (neap tide) are compared. Compared with the spring tide, the difference between the top and bottom layers is smaller. The maximum current speed of the top layer is $\sim 0.7 \mathrm{~m} / \mathrm{s}$, that is, only half of that in the spring tidal period (Figure 12j). The maximum current speed of the bottom layer is $\sim 0.5 \mathrm{~m} / \mathrm{s}$. The water temperature and salinity differences between the high and low tides are also smaller during the neap tide (Figures 12k,n). Note that stratifications of the temperature and salinity were also observed, similar to those of the spring tide. However, the maximum stratification occurred during the low tides, indicating that the warmer and fresher water in the shallower areas during the high tides flowed out to the area close to location P1 and remained in this area during the low tides instead of flowing out further because the distance of the tidal current movement is shorter during the neap tide. Note also that the turbidity during the neap tide is only $\sim 10-15 \%$ of that in the spring tide (Figure $\mathbf{1 2 m}$ ) because the suspension of sediments from the seabed weakened owing to the weaker current. This analysis demonstrates the advantages of the INBUS system. First, the time variation of the water properties can be continuously measured along the sigma layers during both the high and low tides, although the difference in the water surface elevation increases to $\sim 11 \mathrm{~m}$ during the spring tide. In addition, the differences between the water properties of the internal layers can be clearly detected by the INBUS system and, thus, the characteristics of the stratification depending on the tidal phase can be observed and analyzed.

The current buoy system (INBUS-2) is an upgraded version of the original system (INBUS-1), as described in the previous sections. However, the results of field experiments using INBUS2 indicated weaknesses and thus a further upgrade is required. Therefore, a new version of the buoy, INBUS-3, is being designed. The upgrades planned for INBUS-3 are introduced in the following section.

\section{DISCUSSION}

One of the weaknesses of INBUS-2 is that the SSC indirectly measured by the YSI and the ADCP has a low accuracy, which limits the estimation of the sediment distribution under strong tidal current conditions. However, the accurate measurement of the sediment distribution in the water column is important to understand the coastal processes in macrotidal areas. The measured SSC can be used to validate the results of numerical models and thus the data accuracy is important. Other water quality properties, such as the DO or Chl contents, cannot be used to validate the model because the model requires accurate lateral boundary and initial conditions, which cannot be provided. In INBUS-3, this problem will be solved by mounting a LISST sensor (manufactured by Sequoia, United States) on the lifting sensor frame. The LISST sensor is a submersible laser diffractionbased particle size analyzer designed to measure the particle size 

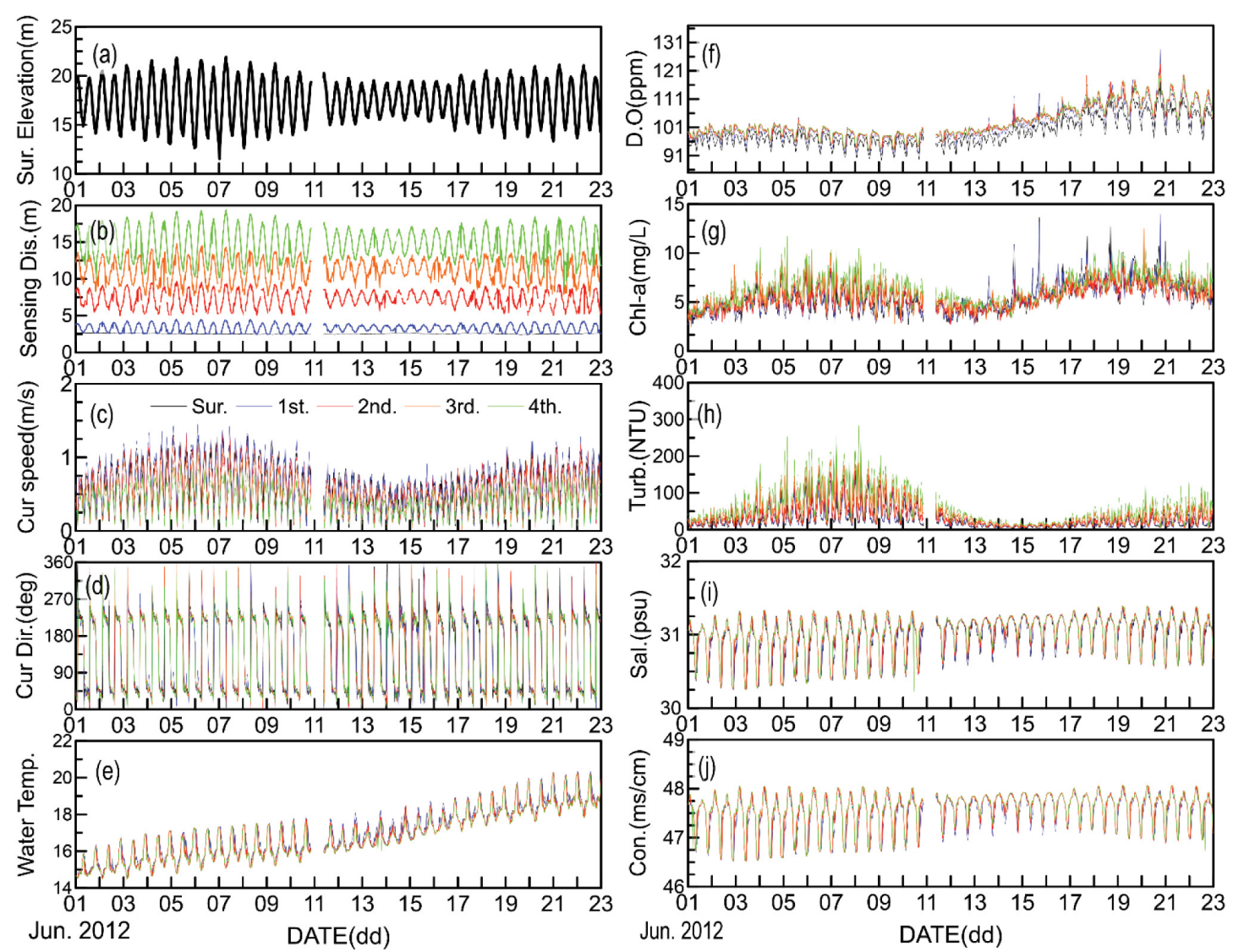

FIGURE 11 | Time variation of water properties measured by INBUS-2 at location P1 from June 1 to 23, 2012: (a) surface elevation, (b) distances from the four internal layers to the seabed, (c) current speed, (d) current direction, (e) water temperature, (f) dissolved oxygen (DO), (g) chlorophyll (Chl), (h) turbidity, (i) salinity, (j) conductivity. Black solid lines, measured at the water surface; blue lines, measured in the first internal layer; red lines, measured in the second internal layer; orange lines, measured in the third internal layer; green lines, measured in the fourth internal layer.

and concentration, which can be used in coastal waters. Because the LISST sensor can measure the SSC with high accuracy, the data can be used for numerical models and to calibrate the YSI and the ADCP data.

Although the LISST can measure the SSC in different layers in the water column based on the vertically moving lifting frame, it cannot detect the SSC close to the seabed, which is important for the determination of the near-bed sediment dynamics. To protect the lifting frame, the maximum water depth to which the lifting frame of INBUS-2 can be lowered is set to $1.0 \mathrm{~m}$ above the seabed. In INBUS-3, the structure of the lifting frame will be modified to allow it to be lowered to $0.3 \mathrm{~m}$ above the seabed for the $N+1$ th layer. As described, the conceptual design of INBUS-3 has been completed. However, because of the increasing cost, its development has been delayed and it is not yet complete. In addition, INBUS-2 has been successfully applied in the areas where its weakness does not pose a serious problem (i.e., where the accuracy of sediment concentration measurement is not necessarily required), which further causes the development of INBUS-3 to be viewed as not very urgent.

Intelligent Buoy System can be effectively applied in macrotidal environments in which the sea surface height significantly changes. The water column can be divided into $N$ layers regardless of changes in the water depth such that the time-dependent water qualities and flow velocities can be measured after the layers are set in a manner similar to the sigma coordinates of numerical models, which benefits the validation of the model results based on that grid system. INBUS was initially designed to monitor marine environments close to tidal power plants (TPPs), which generate power using fast-flowing tidal currents. Marine environments can be significantly changed by the construction of TPPs. INBUS has been successfully applied for the long-term monitoring of the water qualities in areas close to TPPs in which the tidal range is high. The distribution of sediments suspended by strong tidal currents can be effectively determined and thus their effects on the marine environment close to fishing grounds and aquaculture farms can be analyzed.

In addition to macrotidal areas, INBUS is useful for monitoring the water quality near ports, especially those undergoing construction. During the construction of facilities and structures at ports, strong sediment suspension occurs and the sediments flow into nearby fishing grounds and farms, which might have a negative environmental impact. Such sediments may spread horizontally and vertically when they combine with 

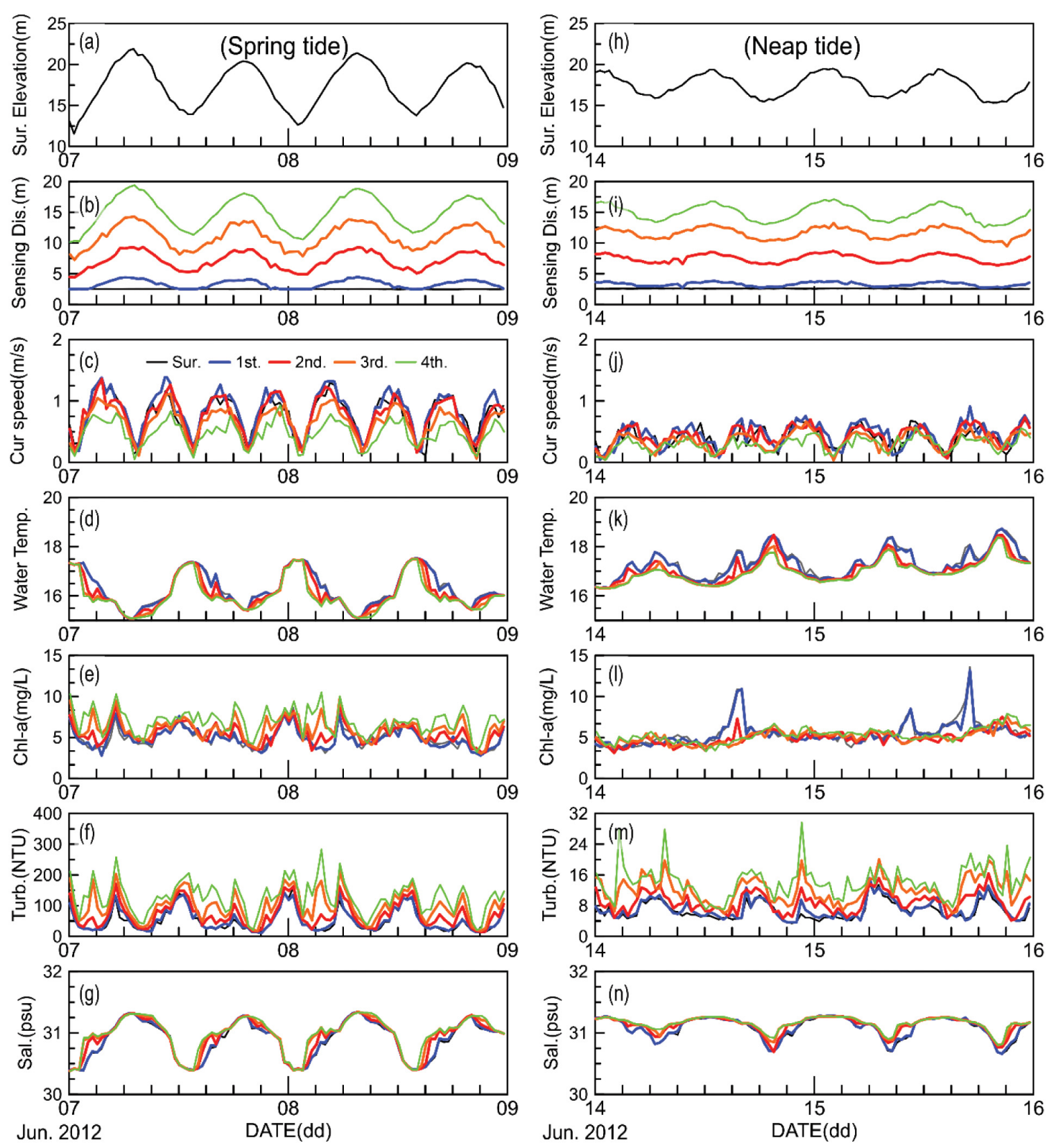

FIGURE 12 | Time variation of the (a) surface elevation, (b) distances from the four internal layers to the seabed, (c) current speed, (d) water temperature, (e) Chl content, (f) turbidity, and (g) salinity over 2 days (June 7-9, 2012) during the spring tide and the time variation of the (h) surface elevation, (i) distances from the four internal layers to the seabed, (j) current speed, (k) water temperature, (I) Chl content, (m) turbidity, and (n) salinity over 2 days (June 14-16, 2012) during the neap tide. Black solid lines, water surface; blue lines, first internal layer; red lines, second internal layer; orange lines, third internal layer; and green lines, fourth internal layer.

tides and/or coastal currents. INBUS has been effectively applied for the monitoring of the water quality variation under such conditions and the results used to establish plans to protect the environment.

Although not planned for the construction of INBUS3, additional upgrades are recommended for future INBUS generations. One of the major purposes of INBUS is the longterm monitoring of the water quality in tide-dominated areas. This requires the sustainable maintenance of the system and sensors. Some of the turbidity, DO, and Chl data collected by INBUS are abnormal, especially during summer, which is due to the contamination of the instruments by the fouling of periphyton adhering to the underwater sensors. In addition to the sensors, fouling could occur on the frame and disturb the motion of the lifting system, which may result in the reduction of the INBUS lifetime. Therefore, it is important to remove the periphyton from the sensor and/or to prevent fouling to increase the maintainability of INBUS; for example, hydro-wipers can 
be used to remove periphyton and prevent biofouling (Cotter et al., 2017). In addition, underwater systems that can be used to prevent the fouling on the bottom of ships have recently been proposed for the reduction of the toxicity of the antifouling paint (Amara et al., 2018; Lagerström et al., 2020). To optimize the buoy system, it may also be necessary to reduce the size of the winch while keeping or even enhancing its efficiency, which requires consideration in future upgrades of INBUS to make it suitable for long-term monitoring in tide-dominated coastal environments.

\section{DATA AVAILABILITY STATEMENT}

The raw data supporting the conclusions of this article will be made available by the authors, without undue reservation.

\section{REFERENCES}

Alexandrakis, G., Manasakis, C., and Kampanis, N. A. (2015). Valuating the effects of beach erosion to tourism revenue. A management perspective. Ocean Coast. Manag. 111, 1-11. doi: 10.1016/j.ocecoaman.2015.04.001

Amara, I., Miled, W., Slama, R. B., and Ladhari, N. (2018). Antifouling processes and toxicity effects of antifouling paints on marine environment. A review. Environ. Toxicol. Pharmacol. 57, 115-130. doi: 10.1016/j.etap.2017.12.001

Bailey, K., Steinberg, C., Davies, C., Galibert, G., Hidas, M., Mcmanus, M. A., et al. (2019). Coastal mooring observing networks and their data products: recommendations for the next decade. Front. Mar. Sci. 6:180. doi: 10.3389/ fmars.2019.00180

Cadier, M., Gorgues, T., LHelguen, S., Sourisseau, M., and Memery, L. (2017). Tidal cycle control of biogeochemical and ecological properties of a macrotidal system. Geophys. Res. Lett. 44, 8453-8462. doi: 10.1002/2017gl074173

Cotter, E., Murphy, P., and Polagye, B. (2017). Benchmarking sensor fusion capabilities of an integrated instrumentation package. Int. J. Mar. Energy 20, 64-79. doi: 10.1016/j.ijome.2017.09.003

Do, J. D., Jin, J. Y., Jeong, W. M., and Chang, Y. S. (2019). Observation of rapid seabed erosion near closure depth during a storm period at Hujeong Beach, South Korea. Geophys. Res. Lett. 46, 9804-9812. doi: 10.1029/2019g1083910

Dorman, C. E., and Winant, C. D. (1995). Buoy observations of the atmosphere along the west coast of the United States, 1981-1990. J. Geophys. Res. Oceans 100, 16029-16044. doi: 10.1029/95jc00964

Fowler, G. A., Hamilton, J. M., Beanlands, B. D., Belliveau, D. J., and Furlong, A. R. (1997). "A wave powered profiler for long term monitoring," in Proceedings of the Oceans'97. MTS/IEEE Conference, Halifax, NS, 225-228.

Herbers, T., Jessen, P., Janssen, T., Colbert, D., and Macmahan, J. (2012). Observing ocean surface waves with GPS-tracked buoys. J. Atmos. Ocean. Technol. 29, 944-959. doi: 10.1175/jtech-d-11-00128.1

Hwang, J. H., Van, S. P., Choi, B.-J., Chang, Y. S., and Kim, Y. H. (2014). The physical processes in the Yellow Sea. Ocean Coast. Manag. 102, 449-457. doi: 10.1016/j.ocecoaman.2014.03.026

Jeong, W. M., Chang, Y. S., Oh, S.-H., and Baek, W. D. (2020). A study on calibration of underestimated wave heights measured by Wave and Tide Gauge (WTG). J. Korean Soc. Coast. Ocean Eng. 32, 296-306. doi: 10.9765/kscoe.2020. 32.5.296

Kang, Y. Q. (1984). An analytic model of tidal waves in the Yellow Sea. J. Mar. Res. 42, 473-485. doi: 10.1357/002224084788506004

Korea Institute of Ocean Science and Technology (KIOST) (2004). Studies on Improving Basic Observation Techniques for Marine Environment (Marine Remote Observation Techniques Development). Techical Rep. BSPE83000-14981 (In Korean). Busan: Korea Institute of Ocean Science and Technology.

Lagerström, M., Ytreberg, E., Wiklund, A.-K. E., and Granhag, L. (2020). Antifouling paints leach copper in excess-study of metal release rates and

\section{AUTHOR CONTRIBUTIONS}

J-SP and J-YJ contributed to the conception and design of the study and wrote sections of the manuscript. JD, S-DH, S-JM, $\mathrm{KH}$, and JP organized the database. JD and $\mathrm{BL}$ performed the statistical analysis. JD, J-YJ, and YC wrote the first draft of the manuscript. All authors contributed to the manuscript revision and read and approved the submitted version.

\section{FUNDING}

This work was supported by the Korea Institute of Ocean Science and Technology (Grant Number PE99932) and the Ministry of Oceans and Fisheries (Grant Number PM62220).

efficacy along a salinity gradient. Water Res. 186:116383. doi: 10.1016/j.watres. 2020.116383

Loisel, H., Stramski, D., Mitchell, B. G., Fell, F., Fournier-Sicre, V., Lemasle, B., et al. (2001). Comparison of the ocean inherent optical properties obtained from measurements and inverse modeling. Appl. Opt. 40, 2384-2397. doi: 10.1364/ao.40.002384

Pedersen, T., Siegel, E., and Wood, J. (2007). "Directional wave measurements from a subsurface buoy with an acoustic wave and current profiler (AWAC)," in Proceedings of the OCEANS 2007, Vancouver, BC, (Piscataway, NJ: IEEE), $1-10$.

Tedesco, M., Bohlen, W. F., Howard-Strobel, M., Cohen, D., and Tebeau, P. (2003). "The Mysound project: building an estuary-wide monitoring network for Long Island Sound, U.S.A," in Coastal Monitoring Partnerships, eds B. D. Melzian, V. Engle, M. McAlister, S. Sandhu, and L. K. Eads (Dordrecht: Springer), 35-42. doi: 10.1007/978-94-017-0299-7_4

Tercier-Waeber, M. L., Buffle, J., Graziottin, F., and Koudelka-Hep, M. (1999). Novel voltametric probe in-situ trace element monitoring. Sea Technol. 40, 74-79.

Woerther, P., and Grouhel, A. (1998). "MAREL: automated measurement network for the coastal environment," in Proceedings of the IEEE Oceanic Engineering Society, OCEANS'98 Conference, Nice, Vol. 2, 1149-1154.

Yanagi, T., and Inoue, K. (1995). Tide and tidal current in the Yellow/East China Seas. Oceanogr. Lit. Rev. 6:425.

Conflict of Interest: S-DH and S-JM were employed by company OCEANTECH Co., Ltd.

The remaining authors declare that the research was conducted in the absence of any commercial or financial relationships that could be construed as a potential conflict of interest.

Publisher's Note: All claims expressed in this article are solely those of the authors and do not necessarily represent those of their affiliated organizations, or those of the publisher, the editors and the reviewers. Any product that may be evaluated in this article, or claim that may be made by its manufacturer, is not guaranteed or endorsed by the publisher.

Copyright (C) 2021 Jin, Dae Do, Park, Park, Lee, Hong, Moon, Hwang and Chang. This is an open-access article distributed under the terms of the Creative Commons Attribution License (CC BY). The use, distribution or reproduction in other forums is permitted, provided the original author(s) and the copyright owner(s) are credited and that the original publication in this journal is cited, in accordance with accepted academic practice. No use, distribution or reproduction is permitted which does not comply with these terms. 